\title{
Gualano + Gualano: Arquitectos. Arquitectura Latinoamericana Emergente
}

Intentando aproximarnos a la producción reciente de arquitectura en el contexto latinoamericano, revisamos algunos proyectos de la oficina uruguaya Gualano+Gualano: Arquitectos. Un trabajo marcado por la influencia del paisaje en que se inserta, pero también por la impronta de formas arquitectónicas contemporáneas que trascienden las fronteras geográficas. Marcelo y Martin Gualano, nos ofrecen un campo de fricción marcado por el encuentro entre la materialización de la obra y el contexto natural, recuperando a la arquitectura como intervención, signo imprescindible de la presencia del hombre en el territorio.

\section{Notas sueltas}

\section{N01 / Realidad}

Gualano + Gualano: Arquitectos, es un estudio uruguayo, que opera desde Montevideo, inserto en una realidad socioeconómica y cultural, que nos define y que define nuestra arquitectura.

Este escenario, desde el cual operamos, ha definido en cierta medida, lo que pensamos y lo que hacemos y lo que podemos hacer.

Producimos desde ámbitos diversos, desde la oficina y desde la facultad; ambos ámbitos de creación y producción de constante aprendizaje.

Dos realidades que se superponen y que se disfrutan de la misma manera.

Nuestra realidad local la tomamos como un marco restrictivo desde donde hacer arquitectura y más que verlo como una cosa negativa, nos gusta verlo como una oportunidad para poder desarrollar arquitectura desde estas realidades y por ende ofrecer una arquitectura de estos lugares.

Austera, responsable, honesta, simple.
Las participaciones en bienales, workshops, conferencias, seminarios, etc., nos han permitido conocer a muchos arquitectos de la región, con los cuales nos sentimos compañeros de ruta, y de los que hemos aprendido mucho y nos dan certezas de que de estos lados del sur, se puede hacer buena arquitectura, y que no va para nada de la mano de la tecnología de punta ni mucho menos.

\section{No2 / Intereses}

El estudio ha encontrado intereses más claros a medida que hemos ido construyendo nuestros proyectos, participado en concursos de arquitectura, participado en encuentros internacionales, dando clases en los talleres de facultad y otro montón de etcéteras.

Esta experiencia del ir haciendo cosas, este crecer; hacen que uno vaya encontrando territorios amigables, en donde se descubren afinidades -espaciales, formales, funcionales, etc.- que empiezan a definir ciertas aproximaciones al hacer, ciertos modos de hacer.

Y ciertos temas que son recurrentes, ciertas arquitecturas que nos enseñan más que otras, con las que nos entendemos más, con las que disfrutamos y nos emocionamos. Y volvemos a mirar y a visitar.

\section{N03 / Sintetizar}

Es encontrar lo justo, lo necesario, ese esfuerzo por encontrar un equilibrio en las decisiones a tomar, en las cosas a representar.

Ni más, ni menos.

Síntesis de programa

Síntesis espaciales

Síntesis del paisaje

Sintetizamos hacia adentro y

sintetizamos el afuera.

Filtrar los datos del paisaje,

de la geografía, de la realidad.

Sintetizar la demanda en un proyecto.

Intentar encontrar los instrumentos, los movimientos, los dispositivos, las piezas que definen la estrategia del proyecto, que lo hacen potente, claro, efectivo.

Síntesis que buscamos a la hora de definir como se posiciona un edificio en el paisaje, como dibuja claramente el gesto, como lo genera.

El proyecto es la síntesis. 


\section{N04 / Amplificar}

De puntos de partida simples, concretos, esquemáticos, sintéticos, encontrar las posibles expansiones y fugas.

\section{Amplificar las decisiones.}

El tiempo en los edificios, las diferentes escalas, las diferentes escalas de aproximación.

A cada doble click, encontrar nuevas espacialidades, nuevas texturas.

Al acercarnos, encontrar bifurcaciones, y al tomarlas descubrir otras.

\section{N05 / Escalas}

Los edificios se plantean desde escalas diferentes.

Se hacen para escalas diferentes, y cada escala tiene su escala.

El skyline la suya.

El paisaje la suya.

El programa la suya.

El usuario la suya.

Las distintas escalas de aproximación al proyecto, las escalas y sus distancias, el fuera de escala, la distorsión de la escala y la escala a escala.

Una textura plantea una fachada de un edificio, que luego es un parasol, que también es un espesor brumoso, que diluye un interior y un exterior, que es un molde prefabricado.

Desde muy lejos y desde muy cerca.

Un banco mide $54 \mathrm{~m}$ de largo.

Una plataforma de 20 × 20 m en una caída de agua.

Un prisma de $80 \times 80 \mathrm{~m}$ en el puerto de Montevideo.

Un molde de 60 × 60 es una fachada.

Nos interesa manipular la escala y

distorsionarla, y trabajar a diferentes escalas, dependiendo por momentos de la distancia del observador, o para qué escala está diseñado el edificio o sus partes.

El edificio responde a cada escala de diferente manera, se expresa de distinta manera.

Entender las diferentes escalas de aproximación, cada distancia tiene su escala, el descubrimiento o la aparición de las nuevas escalas a medida que uno se aproxima a los artefactos.

Lograr distorsiones de escala, construir a varias escalas, sacar de escala las cosas.

\section{N06 / Límites}

El límite como concepto abstracto es casi inherente a la arquitectura, todo es un límite, cada raya que trazamos delimita, marca, define, divide.

Nos interesa el límite como elemento capaz de ser manipulado, dimerizado, tensionado.

La línea punteada, como límite difuso, pero límite.

Un adentro que es un poco afuera, un adentro que termina afuera.

Un arriba que es una plataforma, y un abajo que es una sombra, que es un edificio.

Una plataforma que es una raya en e horizonte, un plano en el paisaje.

Una curva de nivel, un nuevo lugar.

Un edificio que es una raya punteada, que permite ser atravesado, que vincula a un lado y a otro, que separa programa y que los vuelve a unir.

Un edificio que es borde, borde blando, borde activo.

Un entre, entre el banco y el pabellón, que tensiona un espacio largo.

Una fachada, que es una piel ligera, una piel porosa, una bruma espesa, rara, blanca.

Es límite y es cuerpo, y las dos cosas juntas, si estoy cerca o si estoy lejos.

En eso estamos.
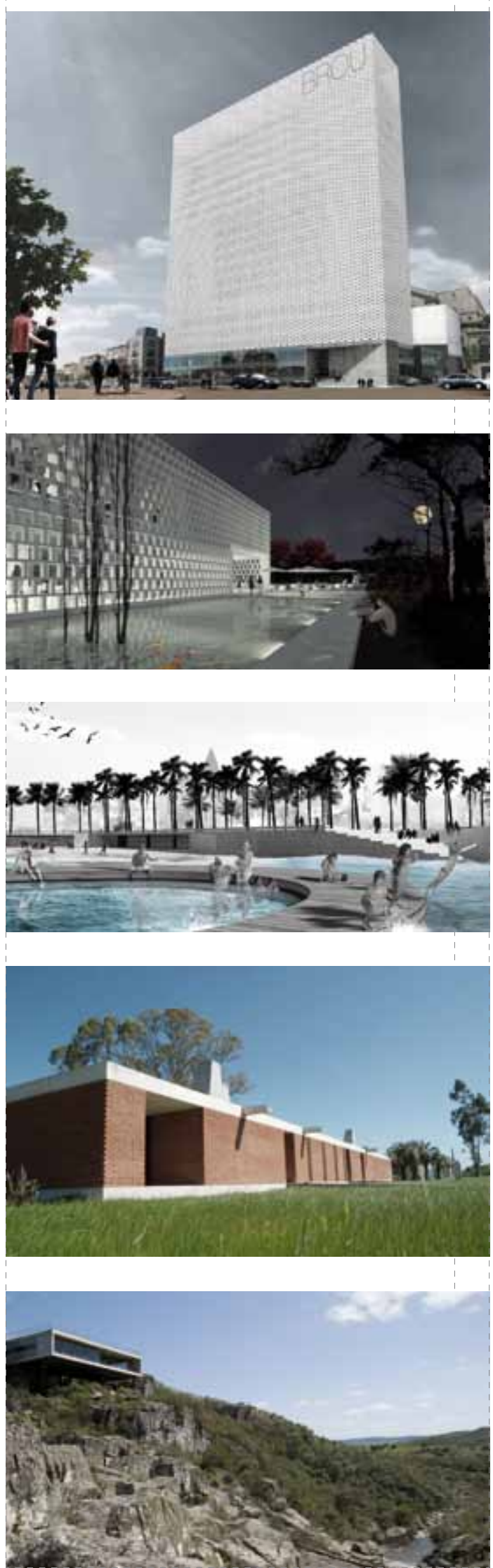


\section{No 21}

de arquitectura
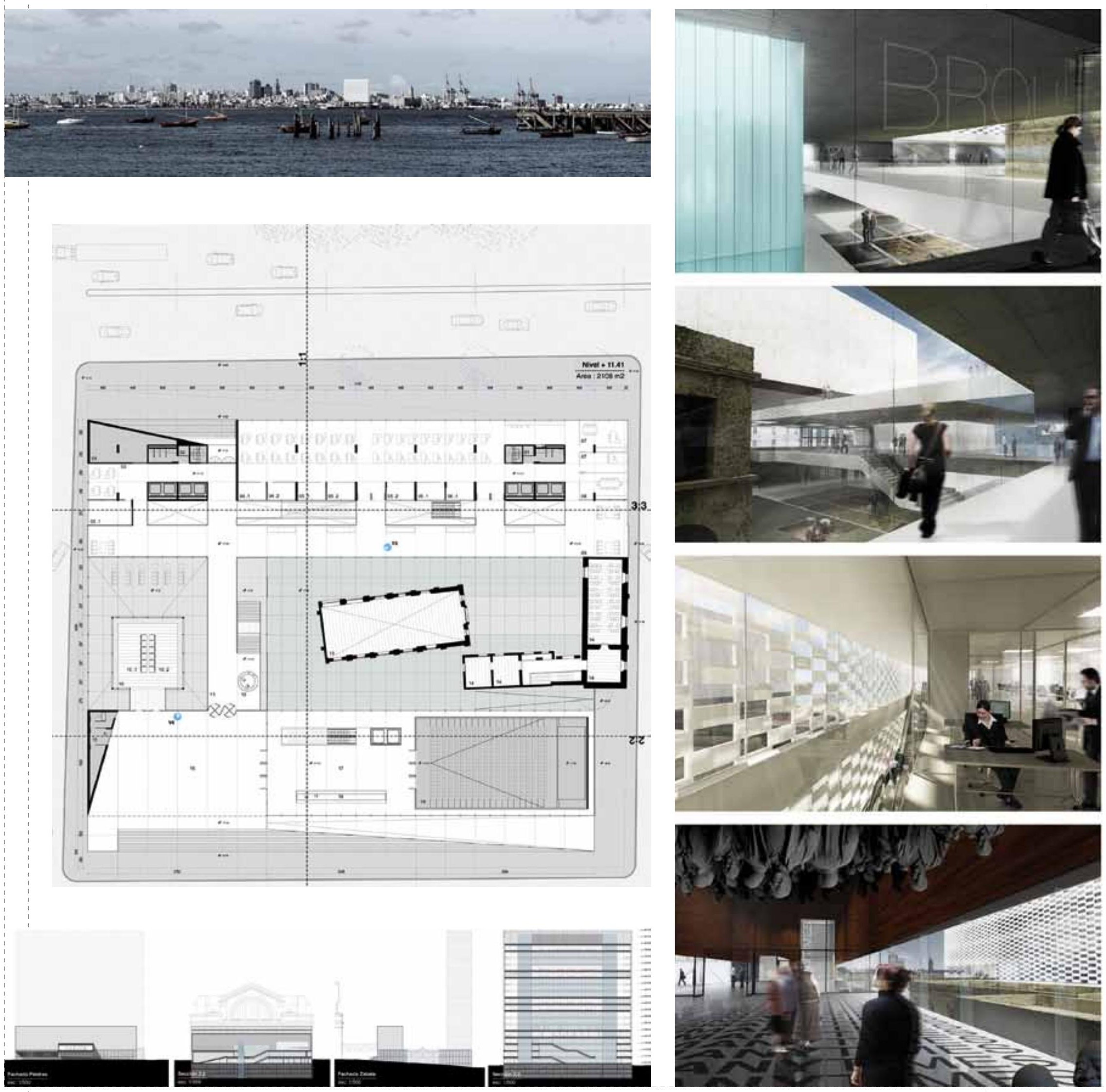


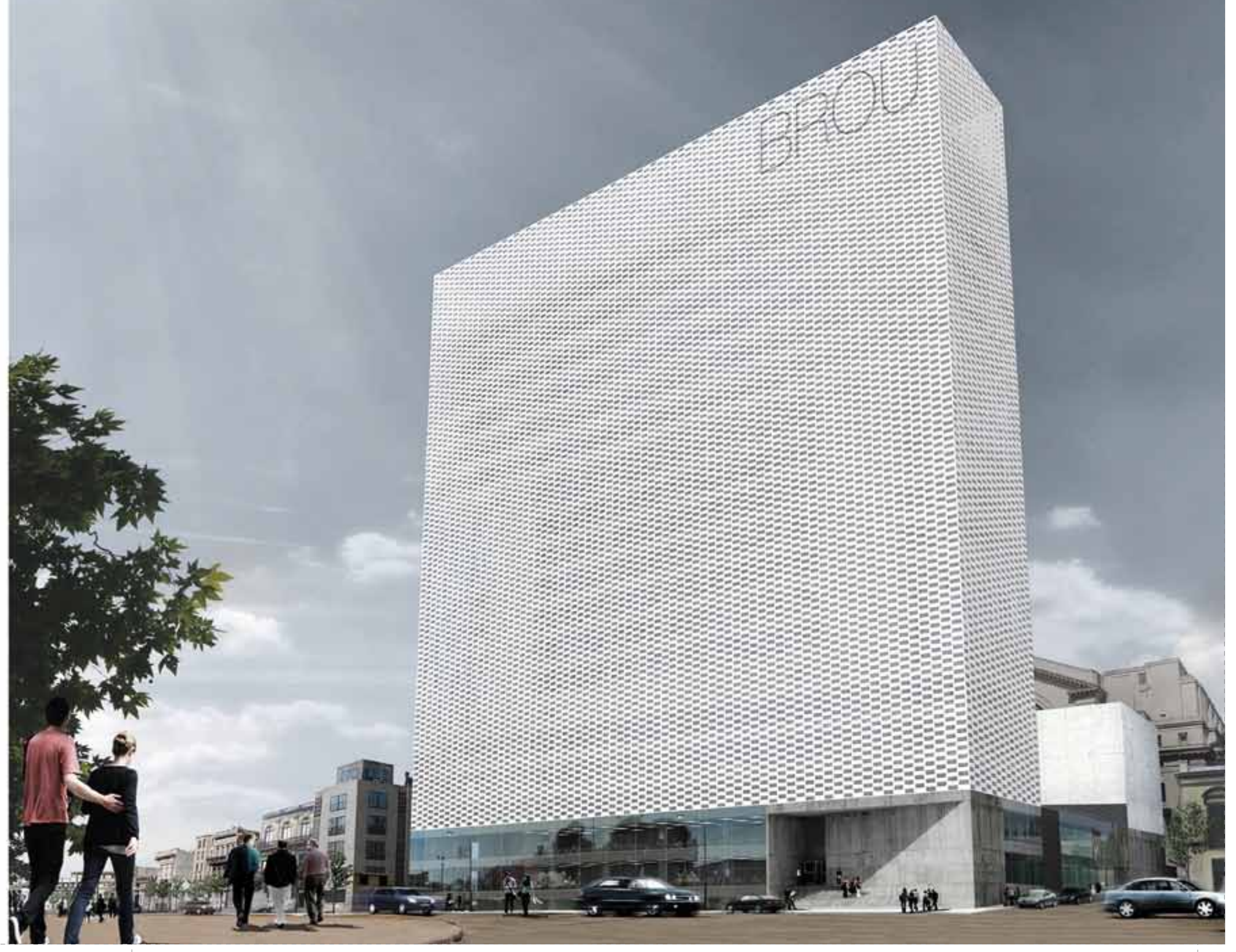




\section{No 21}

e arquitectura
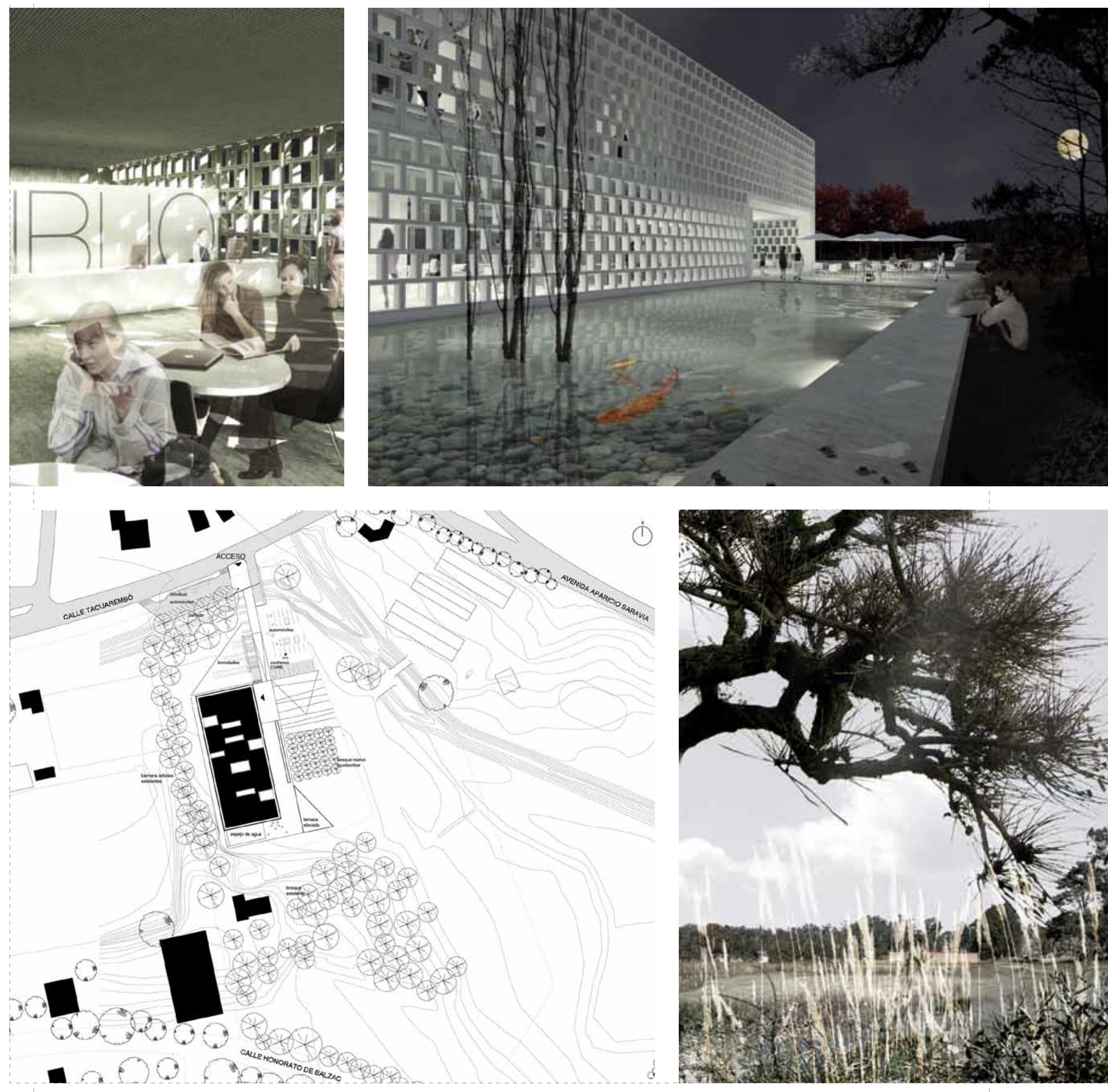
CURE año 200

Concurso Sede Centro Universitario Regional Este, CURE. Proyecto Gualano + Gualano: Arquitectos. Colaboradores: Ignacio De Souza, Elías Martínez, Andrés Varela y Joaquín Mascheroni.
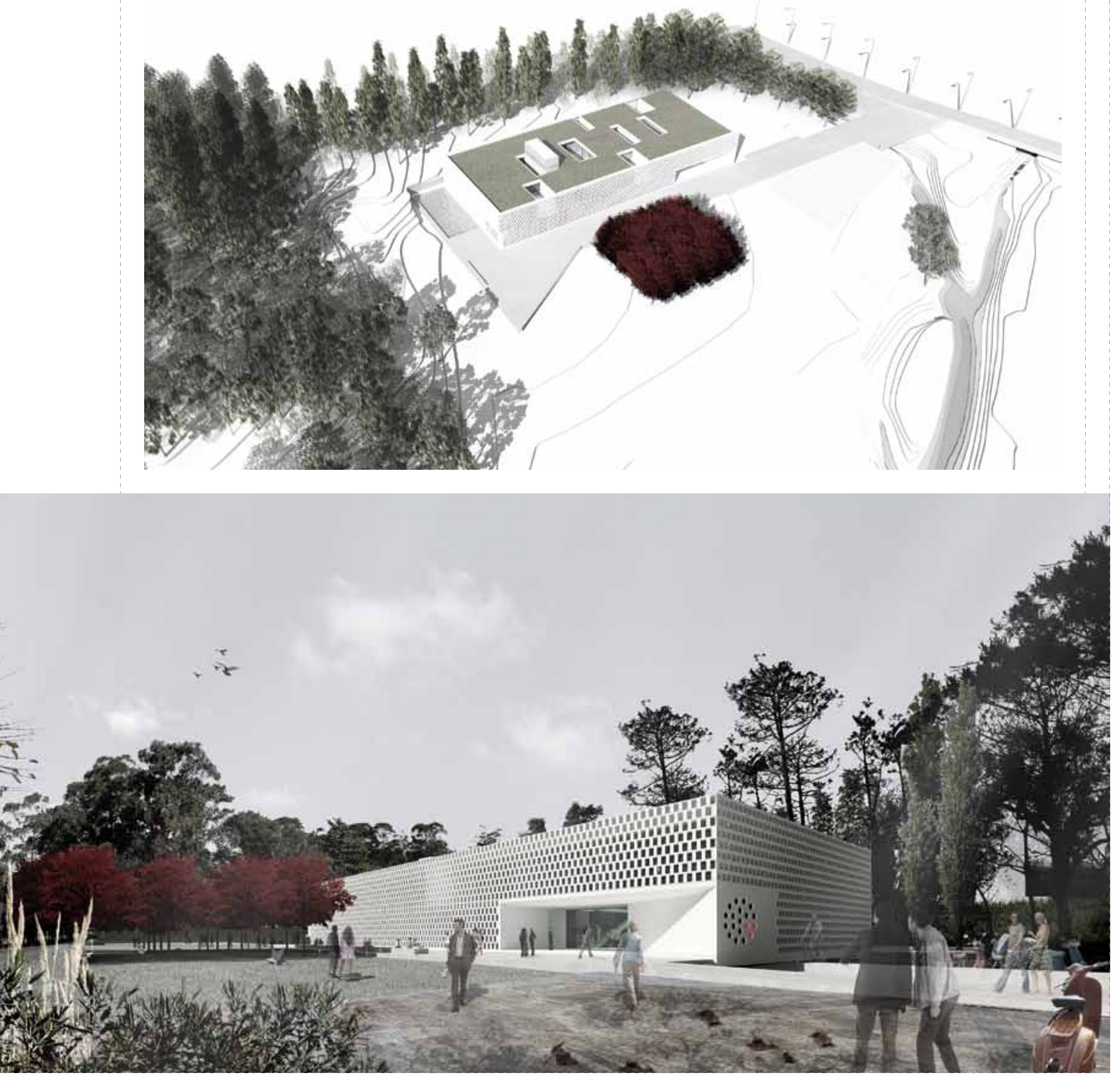


\section{No 21}

de arquitectura
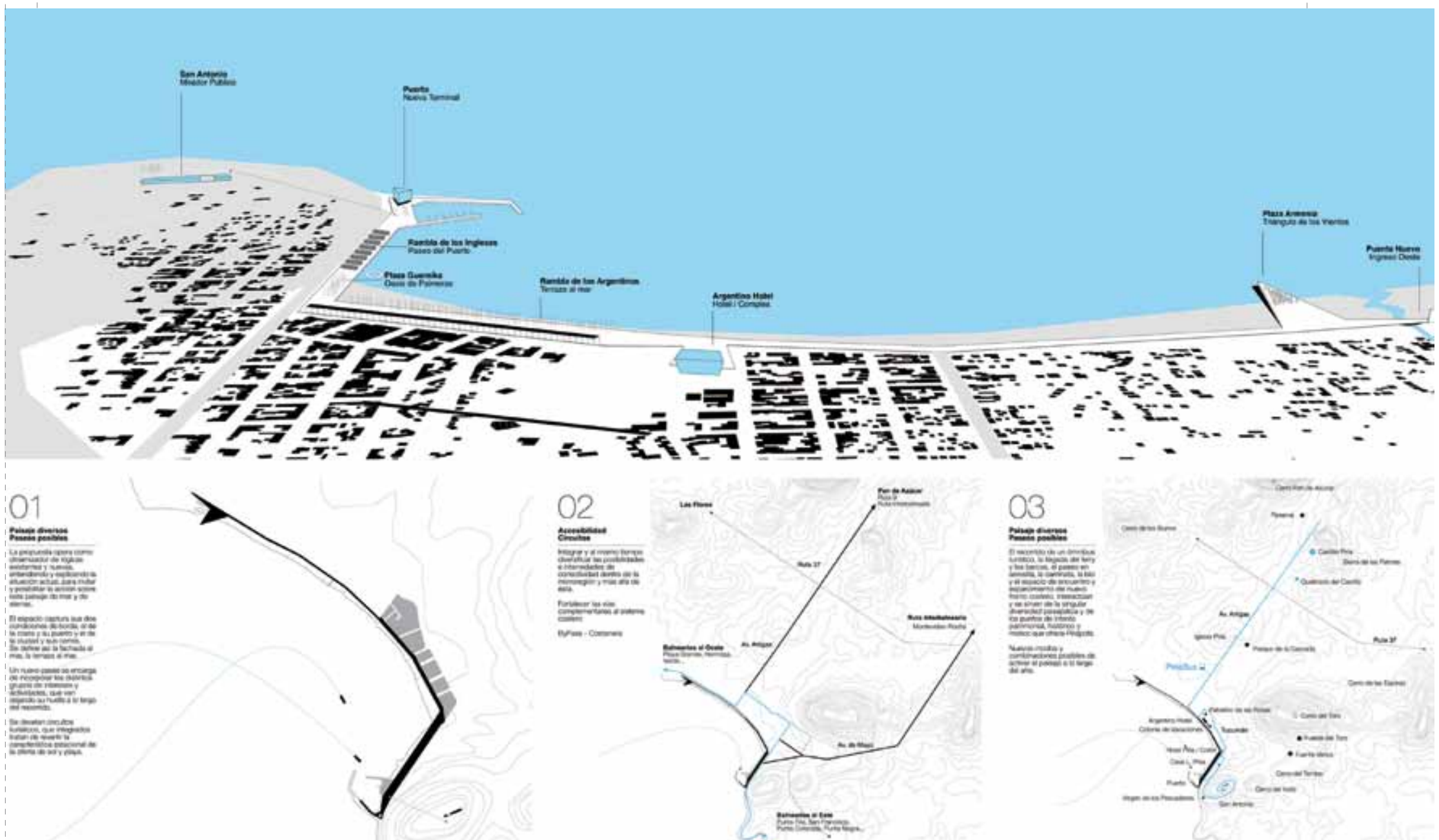

01 푼

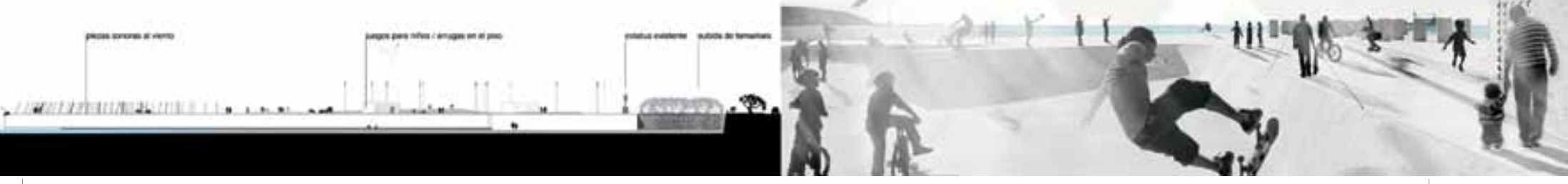

$02 \approx$ 눈

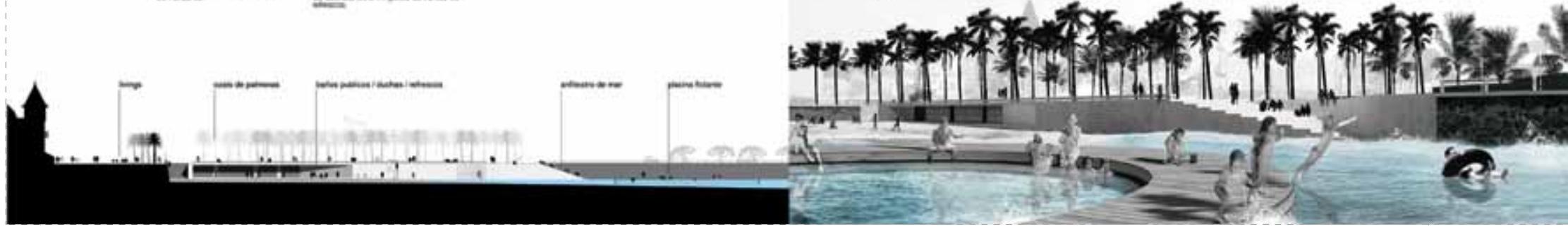


PIRIÁPOLIS

Concurso de Ideas Frente Costero Piriápolis 2025. Uruguay. Proyecto Gualano + Gualano: Arquitectos.
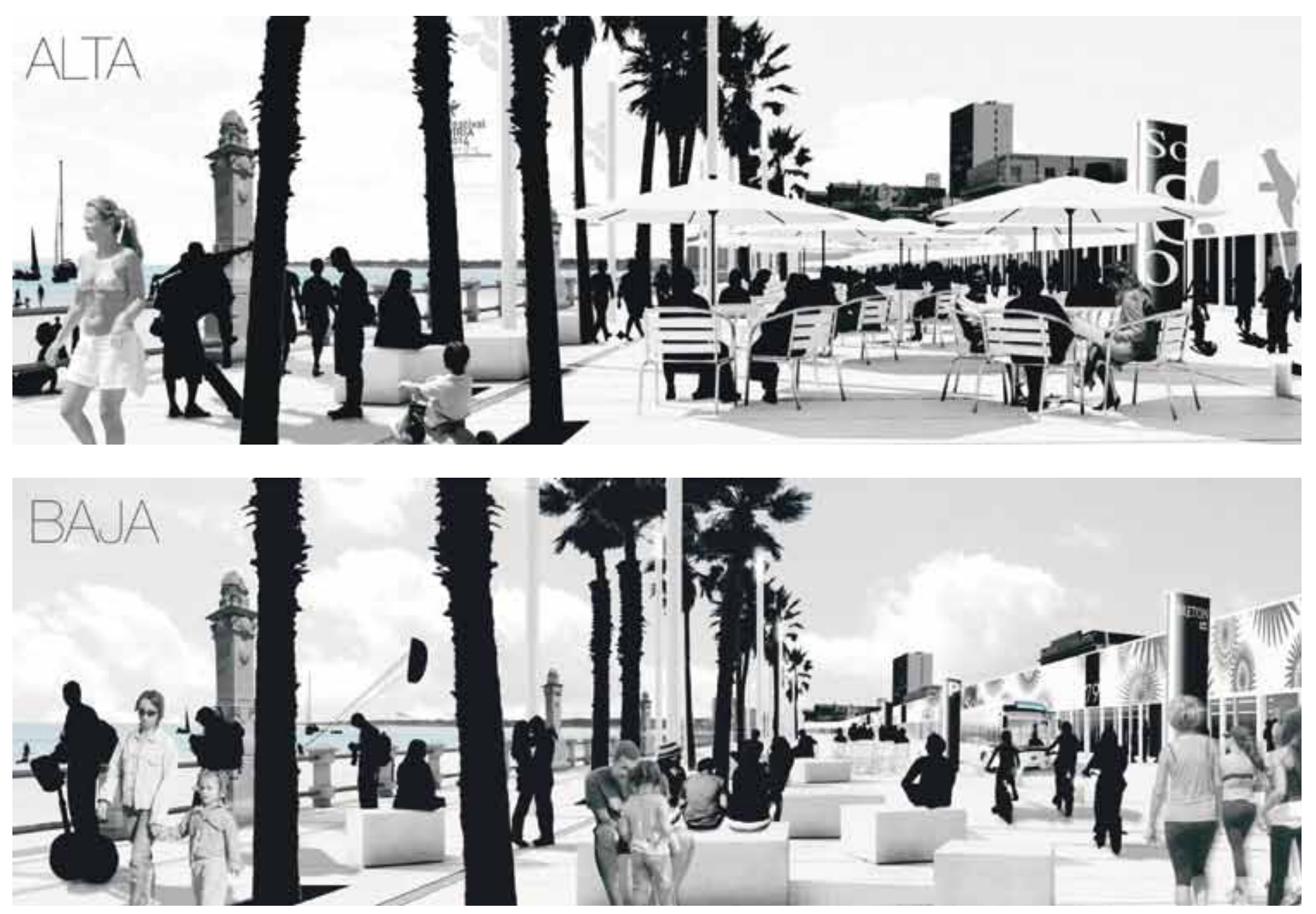

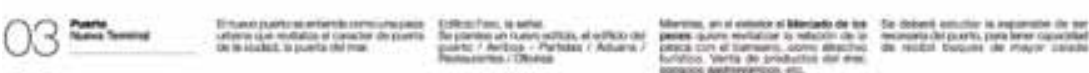

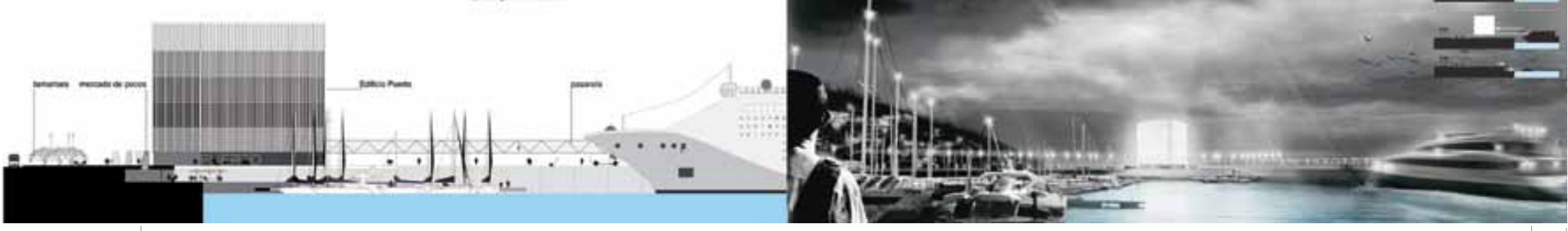

04
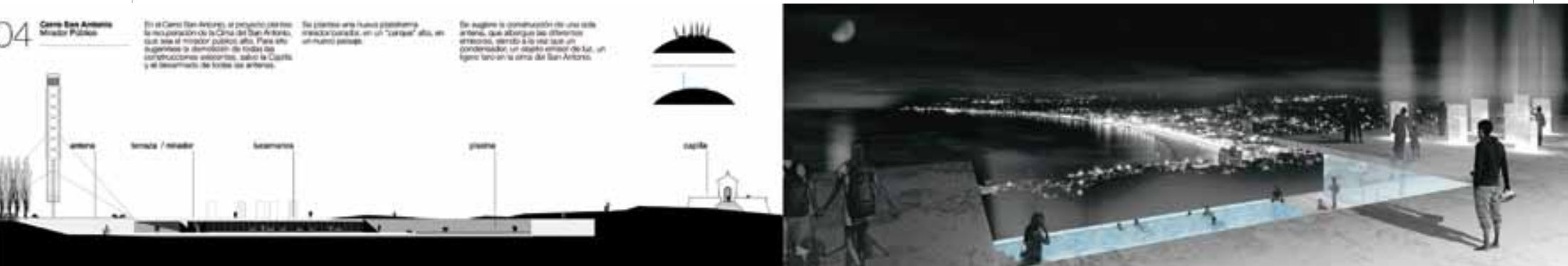


\section{No 21}

de arquitectura
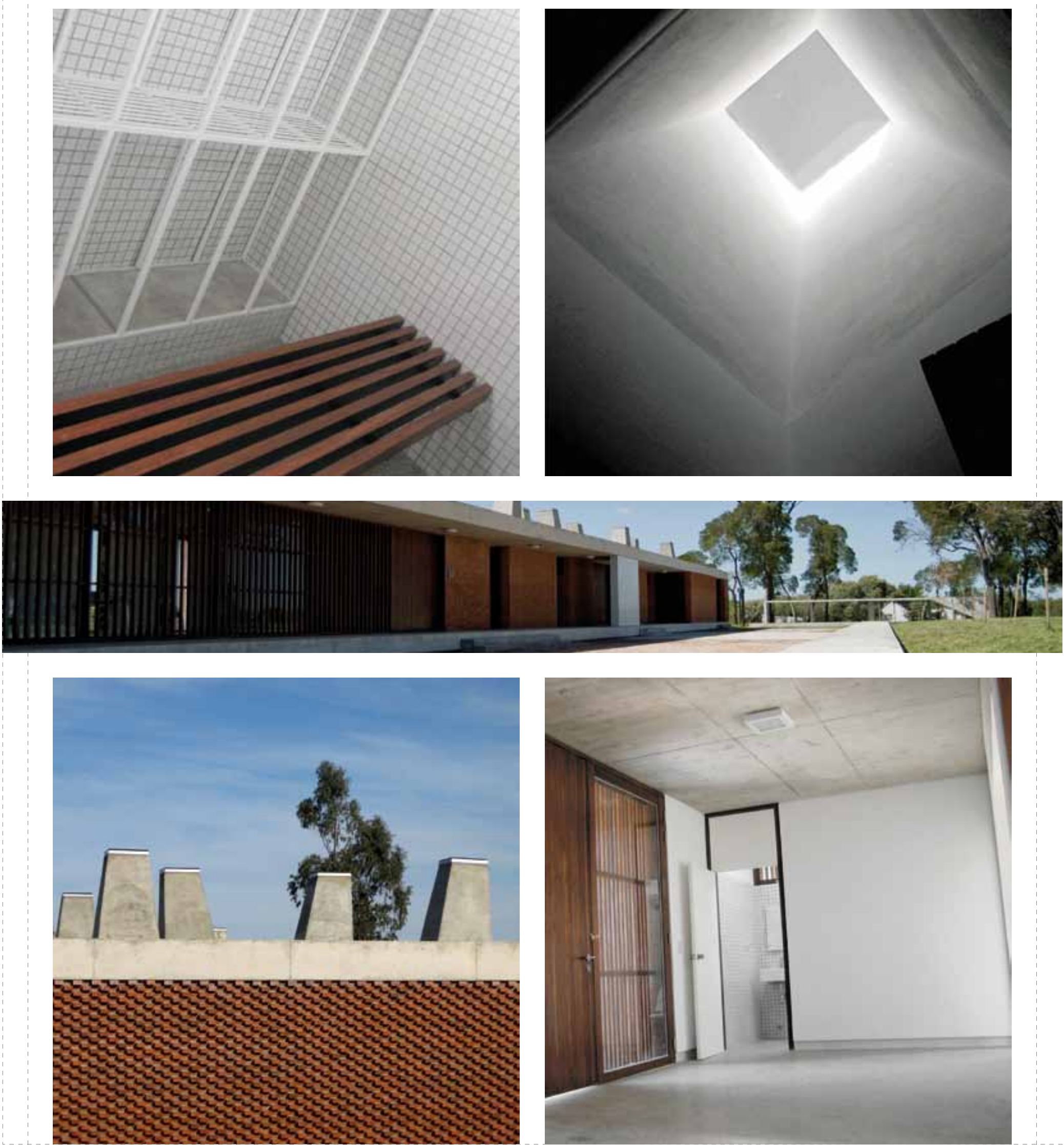
PABELLÓN BOLÍVAR año 2007

Pabellón Pueblo Bolívar. Canelones, Uruguay. Proyecto Gualano + Gualano: Arquitectos.

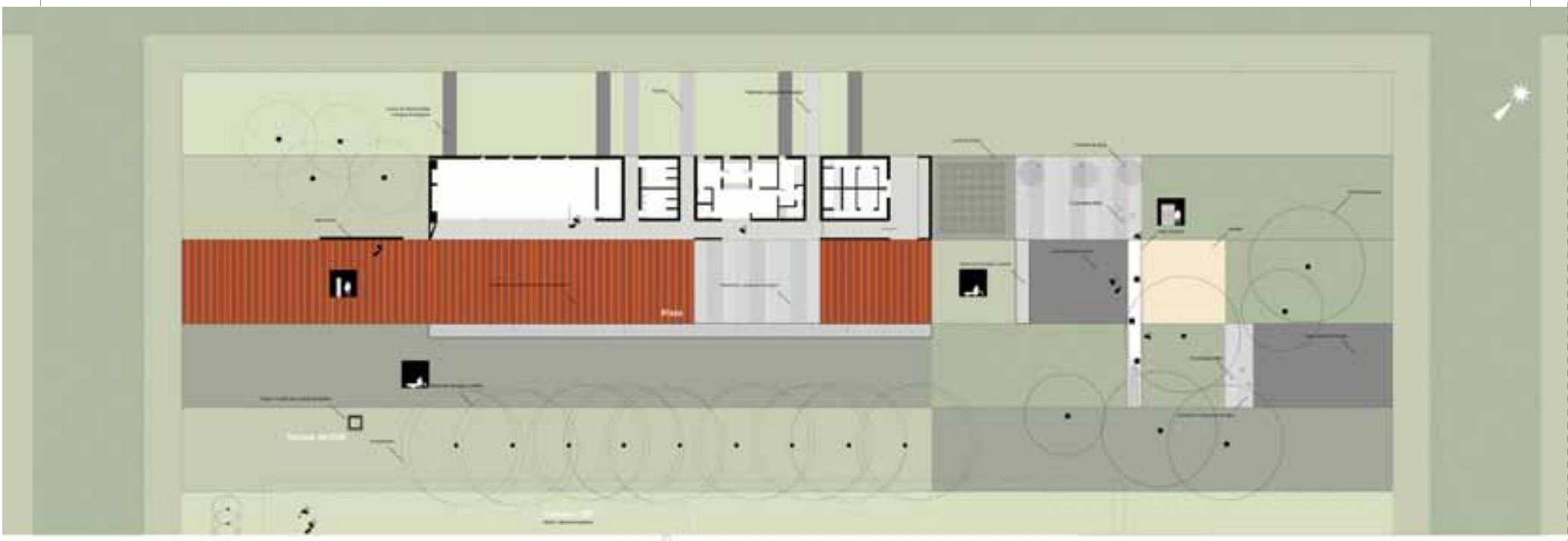

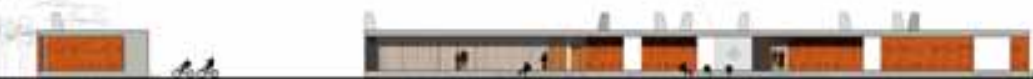

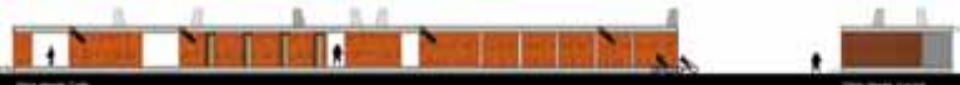

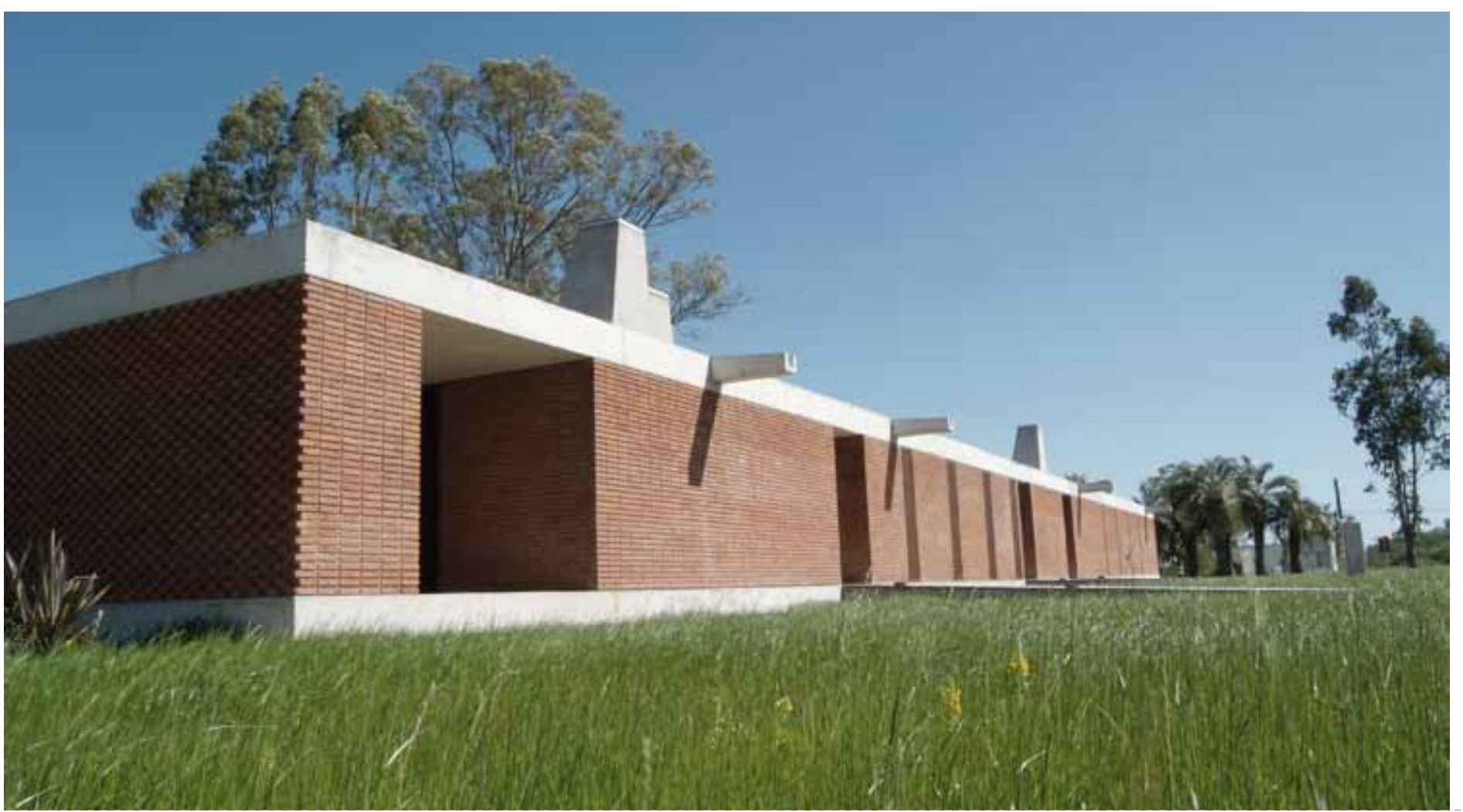



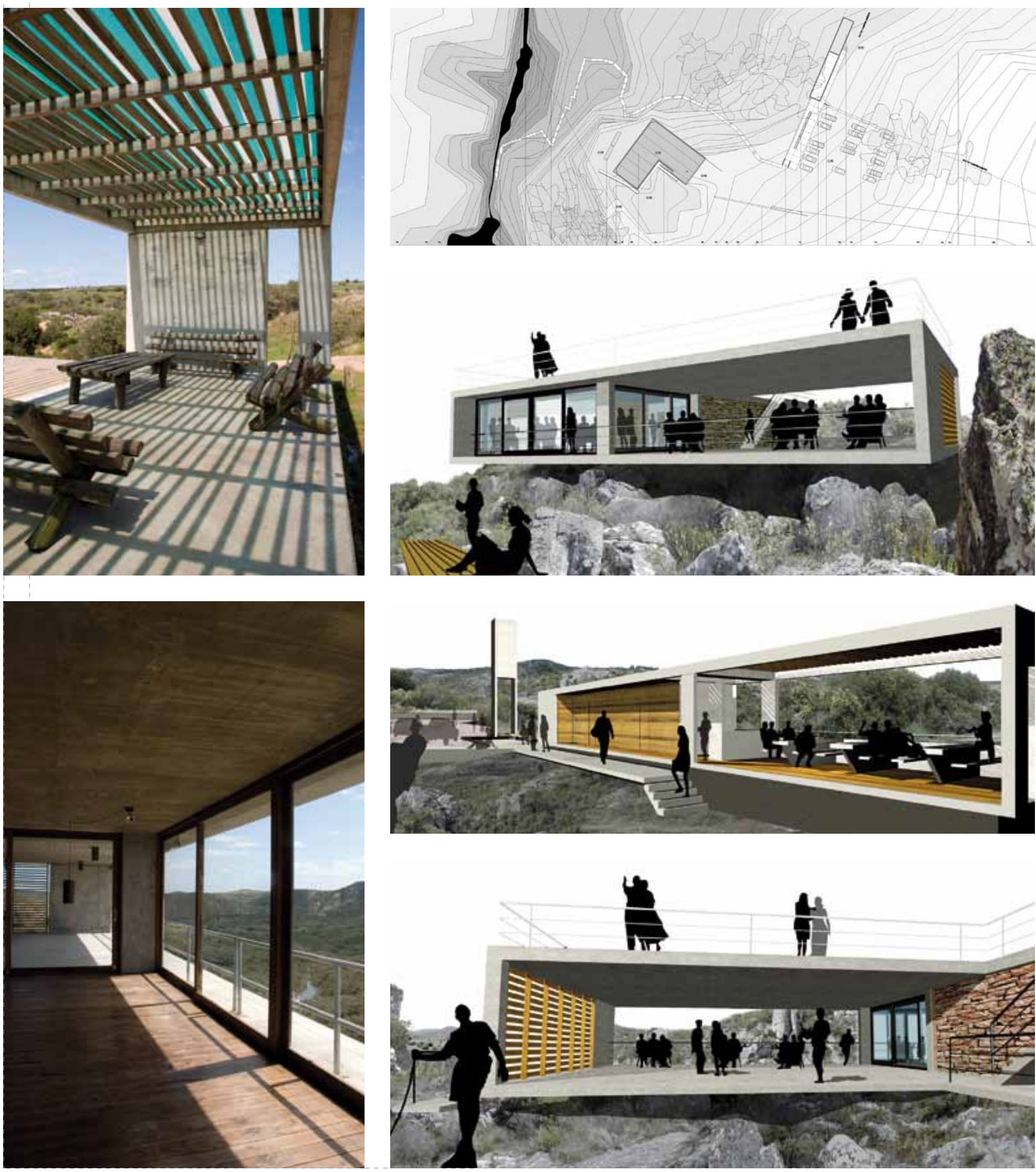
PARADOR PENITENTE años 2003-2004

Parador Penitente. Lavalleja, Salto del Penitente, Uruguay. Proyecto Gualano + Gualano: Arquitectos. Colaboradores: Christian Bernhardt, Lorena Díaz, Jorge Epifanio y Ignacio de Souza.
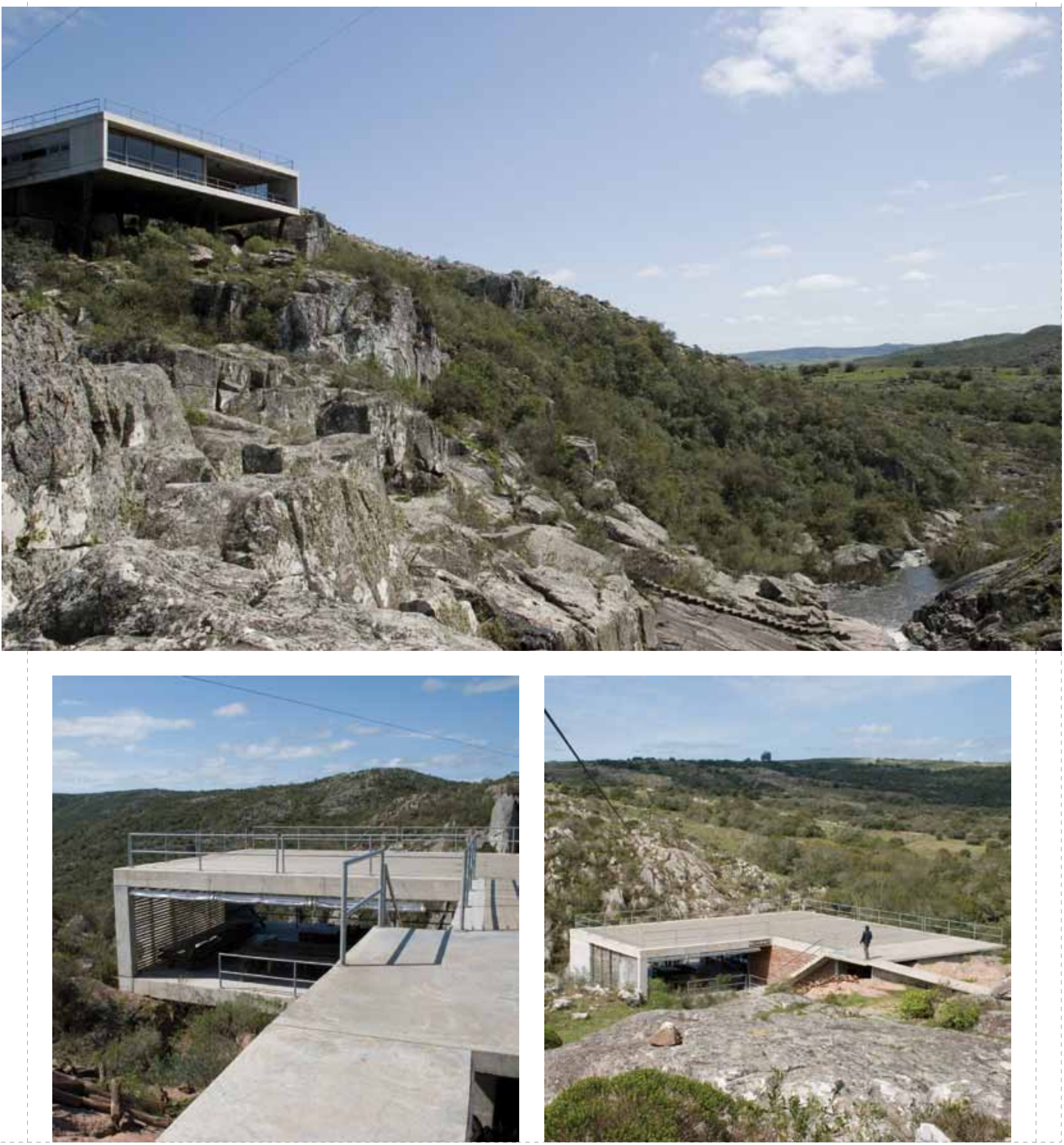